Research/Technical Note

\title{
Guidelines for Medical and Health Protection of Older People in Africa
}

\author{
Ousseynou Ka*, Abdoul Aziz Ndiaye, Awa Gaye, Ndeye Fatou Ngom, Mountaga Elimane Dia, \\ Martial Coly Bop, Cheikh Tacko Diop, Alioune Badara Tall, Boubacar Gueye, Papa Gallo Sow, \\ Lamine Gueye
}

Department of Community Health of the Sustainable Health and Development Training and Research Unit of Alioune Diop University of Bambey, Bambey, Sénégal

Email address:

Ousseynou.ka@uasb.edu.sn (O. Ka)

${ }^{*}$ Corresponding author

\section{To cite this article:}

Ousseynou Ka, Abdoul Aziz Ndiaye, Awa Gaye, Ndeye Fatou Ngom, Mountaga Elimane Dia, Martial Coly Bop, Cheikh Tacko Diop, Alioune Badara Tall, Boubacar Gueye, Papa Gallo Sow, Lamine Gueye. Guidelines for Medical and Health Protection of Older People in Africa. Central African Journal of Public Health. Vol. 5, No. 4, 2019, pp. 142-148. doi: 10.11648/j.cajph.20190504.12

Received: May 12, 2019; Accepted: June 11, 2019; Published: June 24, 2019

\begin{abstract}
To cope with the aging of the population on the horizon in Africa and in particular in Senegal, it is important to set up geronto-geriatric policies adapted to our socio-economic and health context. Thus, in the field of health, the medical and health protection of the elderly, should have a double requirement which consists on the one hand, to prevent the loss of autonomy and on the other hand, in case of illness, even minor, to early diagnosis and appropriate treatment before cascading lesions occur. The main principles or guidelines for a geriatric strategy in Senegal in particular and in Africa in general could be articulated around a policy of home care; the integration of geronto-geriatrics with primary health care, specialized consultation, psychomotor rehabilitation, traditional medico-surgical hospitalization and housing for the elderly. However, any medical and health action in favor of the elderly must first give priority to prevention without neglecting the curative aspect. Thus, this action to be effective should focus on maintaining the home and the family of the elderly, through an urbanization policy that should make possible the cohabitation of ages. On the other hand, the creation of services exclusively reserved for the elderly should for the moment be excluded, since it is culturally inappropriate and economically difficult to implement. It should be emphasized that this medical and health protection for the elderly will require the provision of additional financial resources. However, the organization that will have to cover the cost of this care has yet to be defined.
\end{abstract}

Keywords: Aging, Older People, Health Care Protection, Home Care, Prevention, Senegal, Africa

\section{Introduction}

The number of older people in Africa will rise from 23 million in 1980 to 101 million in the year 2025 [1]. In Senegal, the growth of older people $(3.5 \%)$ far exceeds population growth $(2.7 \%)$ [2-3]. Thus, geronto-geriatric issues will be proportional to these demographic and developmental data, from which we will not yet be released [4]. That is why we now need to implement geronto-geriatric policies adapted to our socio-economic and health context. Among these, the medical and health protection of the elderly must be given priority. It will have a dual requirement: prevention of loss of autonomy and illness, even the last minute, early diagnosis and replacement therapy before the lesions occur massively. Assembled, it is necessary to opt for a part, the integration of the preventive and curative measures, for a part, for the principle of maintenance or return to the home of the elderly patient [5]. The hospitalization will be a last resort and should be done in intermediate health facilities, provided the morbidity of advanced age. These measures must be made on a general guarantee and less costly in money and lives. Thus, the main principles or guidelines for an efficient and effective geriatric strategy in Senegal in particular and in Africa in general, have been articulated around a policy of home care, 
from Geriatrics to primary health care, consultation psychomotor rehabilitation, traditional medico-surgical hospitalization and accommodation for the elderly.

\section{The Home-Keeping Policy}

The psychological support that the elderly person found among the many members of the wider community is lost due to the nuclearization of the family and inadequate urbanization which promotes individualism [6]. For the elderly person as for the other members of his family, he must remain the first resort, provided he continues to exist, and to accept psychologically and materially his role. Awareness of this function requires adequate education and urbanization, as well as technical and financial assistance at home.

\subsection{Education}

To the instrumental and fragmentary vision of man within the family (this separate existence, which socially excludes certain members of the same family) that we encounter in other societies, we could substitute another vision, more in line with this one, with our ethos and our African conception of solidarity. Metaphorically, some argue that "it takes a village to educate a child." Education should be of interest to both the child, the adult and the elderly, with, however, goals for each generation:

a: the child: education should be concerned with inculpating in the child the notion of family solidarity, help for the elderly, respect due to their age, their wisdom, their knowledge and experiences of life.

b: the adult: wherever there is a loss of parental authority, education must tend towards a restoration of parental authority. Thus, the actual presence of fathers and / or mothers within the family, could promote education by example. In fact, parents' attitudes towards grandparents favorably influence the child's behavior and prepare him psychologically for his future filial duties, at the various stages of his own life.

c: the elderly person: the maintenance of physical activity during his or her adult life, prepares for a better organic aging. In addition, the knowledge held by the older person gives him or her a feeling of usefulness, value and self-esteem. Spirituality can also contribute to one's balance. Indeed, in Senegal and everywhere in Africa, houses of worship (churches, mosques...), play a beneficial role on the psychological and social level [7].

\subsection{Urbanization}

It is the role of architects and urban planners, to create, based on sociological and cultural data, places of residence and a sufficiently friendly environment, to make possible the cohabitation of the three generations. Thus, any urbanization policy that favors the meeting of the generations, seems to us to be the first remedy against the progressive loss of autonomy related to old age, the isolation and the depression of the elderly person. Indeed, the maintenance of the social link with the people of its environment; seems to have a positive influence on the psychological balance of the elderly person, while at the same time, it constitutes, through intergenerational dialogue, a means of combating juvenile delinquency.

\subsection{Help and Home Care}

On the proposal of a health checker or social worker, it should be possible for a neighborhood committee or a rural community, responsible for managing primary health care, to decide each elderly person taken individually from the temporary or extended opportunity of a home help-assistant, but also from home-based health care [8].

The organization of African solidarity, based on tradition or religion (rights of kinship by blood or rights by the neighborhood, duties towards the elderly, duties of visiting the sick...) could be revisited to help older people, while having the concern to avoid creating at home, a mentality of assisted consisting of confining them in a role which reduces them to receive without giving anything in return. This renovated organization could, according to methods to be defined with the elderly, put their experience capital and their social capital (network of relationship of mutual knowledge) at the disposal of the community.

\subsection{Financial Aid}

It would be burying its head in the sand, to deny that population aging is accompanied by an increasingly worrying uncertainty about the ability to finance pensions and the minimum allocation of resources. It is important to emphasize, once again, the vital importance of family and subsidiary solidarity before that of the state. But this solidarity is more and more, facing economic difficulties and currently present limits.

\section{Integration of Geronto-Geriatrics with Primary Health Care}

The current medical and health organization in Senegal, based essentially on the primary health care system (Table 1), tends to be superimposed on the administrative division. The latter, and the corresponding medical and health structure, may be the support of a geriatric health care organization, provided, however, that they are accompanied by adequate logistical means and qualified personnel [9]. Geriatric staff should include:

\subsection{The Auxiliary Family of Care}

For a care and nursing action, it could be proposed to any family with an elderly person sick or not, the training in home care of two of its members, if possible of the same sex as the they are responsible for helping in their daily activities. For this, training is obviously necessary, for a period of one month for example, dealing with a rudimentary program of geriatric awareness, relating to the knowledge of organic aging, the risk of physical and psychological trauma, iatrogenic risk and the 
morbid or even mortal risk of any affection, even the most benign. The training will also cover body hygiene and especially food. At a more advanced degree of morbidity or loss of autonomy, a caregiver could work part-time, provide services to the family, and the periodicity and duration of his visits could be fixed by the health committee.

Table 1. Primary Health Care Structures, Current Staff and Proposed Staff for Geriatrics.

\begin{tabular}{|c|c|c|c|}
\hline Structure & Care and hospitality structures & Current staff & Geriatrics staff (proposed) \\
\hline & Home & & $\begin{array}{l}\text { - Family member } \\
\text { - help-housewife } \\
\text { - nursing auxiliary }\end{array}$ \\
\hline Village & Health Box & $\begin{array}{l}\text {-Community health worker } \\
\text {-Matrons }\end{array}$ & $\begin{array}{l}\text { - Geriatric health controller } \\
\text { - Community health worker }\end{array}$ \\
\hline District & Health Post & $\begin{array}{l}\text {-State nurse } \\
\text {-Sanitation or sanitary agent }\end{array}$ & $\begin{array}{l}\text {-Specialist nurse } \\
\text {-Health worker } \\
\text {-Social assistant } \\
\text {-Physiotherapist } \\
\text {-Dietitian }\end{array}$ \\
\hline $\begin{array}{l}\text { Department } \\
\text { Region }\end{array}$ & $\begin{array}{l}\text { Health Center } \\
\text { Regional Hospital }\end{array}$ & $\begin{array}{l}\text {-Doctor } \\
\text {-Dental surgeon } \\
\text {-Midwives } \\
\text {-Pharmacist }\end{array}$ & $\begin{array}{l}\text {-Doctor (geriatrics) } \\
\text {-Specialist nurses } \\
\text {-Auxiliary staff } \\
\text {-Social worker } \\
\text {-Hospitalization in general services }\end{array}$ \\
\hline
\end{tabular}

\subsection{The Geriatric Controller}

It must have a training focused on hygiene and community cleanliness, animation, awareness of neighbors, goodwill and local authorities (health committee, customary or religious notabilities, district chiefs) to the state of such and such elderly person and finally on the rights of the people (pensions, allowances, fiscal rights, Plan Sesame or policy of gratuitous care, certificates of indigence....)

\subsection{The Community Health Worker}

It must be able to consolidate or re-establish defective family relationships, detect in the environment of the elderly, pathogenic factors that require remediation and prophylaxis, to provide nursing and to teach them to family members in particular, elements of masso-physiotherapy and functional rehabilitation. It is better for this agent to be an elderly person and thus to encourage communication by peers, more adapted to our socio-cultural realities, since it is difficult or even uncomfortable for a young person to talk to his elders about problems of sexuality, prostate....

\subsection{The Social Worker}

The social worker specializes in the help and support relationship, he / she can also act as an interface between the family and the other structures of which the person elderly needs. In this respect, he / she supports elderly people who are experiencing economic, social or psychological difficulties. After analyzing the situation of the elderly person, the social worker proposes possible solutions in agreement with the family. The social workers at the hospital's social service inform, guide and assist elderly patients and their families. They allow them, access to care and rights (Plan Sesame or policy of free care for the elderly, financial aid municipal....) But also the organization of the conditions of exit of the patient, and continuity of care.

\subsection{The Dietitian}

He brings his scientific and technical skills, to ensure the nutritional balance of meals, the establishment of individualized diets on medical prescription, the nutritional quality of food and food preparations, and compliance with hygiene rules. He works in collaboration with the doctors, the paramedical personnel, but especially supports the elderly person and his family.

\subsection{The Geriatric Medical Care Team}

The district health manager, the health center-based team, should include a specialized nurse, a health worker, a social worker, a physiotherapist and a specialized dietician in the care of the elderly. It exercises control over all the staff mentioned above. Bearing this in mind, she may be required to conduct knowledge check tours and application of standards at the health hut level. The combined action of the family, the geriatric controller, the community health worker, the primary care medical team, should aim to prevent loss of independence and therefore physical well-being and psychic of the elderly, diagnosis and early treatment, home maintenance. Moreover, it is necessary to avoid as much as possible, the hospitalization which could be for this subject psychically and physically fragile, immunodepressed, a factor of morbid risk, immobilization and bedridden state. The implementation of such teams in developed countries, seeking to repair their errors in the field of geriatrics, has proved its effectiveness: around the treating physician [11-12].

\subsection{The General Practitioner}

In everyday life, it is the general practitioner who receives the sick elderly person; if he plays his score insufficiently, it is because the curriculum of medical studies has not given sufficient space to the undeveloped objectives of elderly medicine. Is it useful at the level of the department, to provide 
next to the doctor of the health center, a doctor specialized in geriatrics? The census of the elderly and their state of morbidity, variable in time and space, can provide the answer. Thus, for the general practitioner to assume his role and function, it is important that he be trained on basic rules in geronto-geriatrics.

\subsection{The Geriatrician}

The ideal is to assign a doctor-geriatrician in each health center, with medical responsibility extended to the elderly department and geriatric teams of districts. There will be a consultation room, a treatment room and some hospital beds; the admission of the elderly person under his sole responsibility. His mission will be to control diagnostic and home care standards. In fact, its activity should be dominated by the surveillance and prevention of the especially chronic pathologies of people over 60 years old. It could also provide for medical consultations which, at the departmental level, should be at the top of the geriatric organization (Table 2).

Table 2. Geriatric Care Organization at Departmental Level.

\begin{tabular}{llll}
\hline Home & Health box & Health post & Health center \\
\hline -Help-housewife & -Prophylaxis & -Home care & -Geriatric consultation \\
-Help for the essential & -Body hygiene & -Physical rehabilitation & -Hospitalization \\
acts of life & -Food hygiene & -Family education and the & -Home care coordination \\
-Nursing & -Nutrition & & \\
Reference and counter reference & & & \\
\hline
\end{tabular}

\section{Specialized Geriatric Consultation}

\subsection{Specialized Consultation}

In fact, any general practitioner should be able to open a medical file for an aging patient at the health center level, and follow it up with periodic check-ups. Specialized consultation in geriatrics should instead focus on education and the determination of normative prevention rules for individuals, families and technical staff in the health box and the health post. The experience of the Pension Provident Institute of Senegal (IPRES) proves that the care in one place of the elderly pensioner and his family is possible and offers among other benefits, the maintenance of a community that does not isolate not the elderly person. It can, however, be improved by the presence of specialized staff.

The first consultation will include:

a: a health check-up from the age of 40 , for example, which will take into account the anamnestic data of the current diseases, the antecedents, the data of the previous and current clinical examinations, the family network and the quality of the affective relations;

b: a clinical and biological assessment: renal, pulmonary, cardiac, neurosensory, vascular metabolism; such a balance sheet could be repeated every year.

A second consultation with the geriatrics team at the center will focus on talks, for a popular education for healthy aging or Popular Action Education for Aging "APEV". This talk will focus on organic aging, risks for the elderly, food and body hygiene, the rights of the elderly, etc....) to cap it all on the "age well".

A third consultation of control, evaluation of the understanding of the received advices will be programmed.

\subsection{Specialized Care Actions}

They will include conventional care and psychomotor rehabilitation. a: Traditional care: They do not pose any particular problems apart from the necessary adjustment of doses because of visceral, hepatic, cardiac and renal defects; however, the elderly person's psychological approach requires human qualities of patience, respect, empathy and affection.

b: Psychomotor rehabilitation: It becomes one of the basic requirements of geriatric care (Table 3). A rehabilitation room should be provided in each health center, for the use not only of the elderly, but also of the physically handicapped younger. The staff will consist of a physiotherapist specializing in the rehabilitation of the elderly, a social worker or an educator specialized in elderly psychotherapy, and a community health worker. Each center should be equipped with massage equipment and physiotherapy adapted to the elderly person. The sending of the patient to rehabilitation will be decided by the doctor-geriatrician and the mode of rehabilitation will be established by the physiotherapist, because the geriatric rehabilitation must be specialized (difficulties of adaptation to the effort, the poly-pathology, the psychological aspects...), versatile (neurological, motor, psychic...), multidisciplinary (physio, ergo, psycho, socio, ludo-therapy...), intensive (without loss of time...) and tenacious (need for continuity in the effort and must have a service of suites because of the fragility of the acquis..). These last two conditions will be fully met with the help of the community health worker and the family.

Table 3. Organization of Psychomotor Rehabilitation.

\begin{tabular}{ll}
\hline Home/Health box & Posts and Health centers \\
\hline Suite service & Rehabilitation service \\
-Massage therapic clinic & -Physiotherapy \\
-Psychotherapy & -Ergotherapy \\
-Sociotherapy & -Psychotherapy \\
Reference and counter reference & \\
\hline
\end{tabular}

\subsection{The Financial Support of the Consultation and the Care}

In the current state of the choice of Senegal, the care of the elderly do not excessively overburden the collective charge 
and the family support lessens the expenses of the State. What will happen when the number of older people increases and when individualism and the loss of family supports replace community life? Regardless of the current individual or family participation, one day the question will arise as to which organization will pay the cost of caring for the elderly. It is important to underline that in both Senegal and throughout Africa, the number of elderly people receiving a pension and / or retirement allowance is unfortunately a privileged minority.

In the field of gerontology, several ministries are directly involved in different ways, and contribute to the physical and mental well-being of the elderly (ministries of labor, social action health, living environment, family...). The formula that will allow them to finance both pensions and allowances, care and hospitalization remains to be found and it will be solicited the collaboration of employers, institutions for sickness, and perhaps one day the Agricultural Cooperative Funds.

\section{Hospitalization of the Elderly}

The hospitalization of the elderly should be avoided as much as possible but if it proves to be essential, it will be carried out with the aim of a quick return to the home, because it is the best prevention of the bedridden state [5-8]. This will include the continuation of hospitalization in the general services and part-time hospitalization.

\subsection{Maintaining Hospitalization in the General Services}

It is for this reason that a priori, the creation of geriatric hospitals must, for the time being, be deferred in underdeveloped countries, since they are culturally unsuitable and economically difficult to realize for resource deficiencies. In addition, it is questionable whether the deprivation, the impecuniosity of the families would not be pretexts to the abandonment of the elderly hospitalized? Exceptionally, only rare long-stay services for elderly people suffering from major psychiatric conditions could be accepted, making home-care impossible [10]. Hospitalization in the general services is a reasonable proposition and a quota of $10 \%$ of beds could be reserved for the elderly; other types of hospitalization may be offered.

\subsection{Part-Time Hospitalization}

It will include:

a: Overnight hospitalization: this is the admission of patients for the night, only between 19:00 and 07:00 am the next day. The patient will return to his family during the day. It can be done in the general services. It is a therapeutic solution offering a safe place to certain pathological situations (phobic neurosis, anxiety neurosis, depressive state, delirium..) as well as a reintegration solution in particular, for some isolated outgoing victims prey to the anxiety of nocturnal loneliness. It also offers a solution for home support, for some demented with age or sleep disorders. It also relieves families especially if the elderly person is suffering from certain psychiatric conditions. But, it will have the disadvantage of all the hospitalizations part-time (continuity of benefits...) [13-14].

b: Day hospitalization: it concerns the most varied affections; it allows rapid diagnosis of clinical and para-clinical, but also, the early start of appropriate treatments. It is functional from Monday to Friday at normal times and the patient returns home at night. The frequency of hospitalization depends on the severity of the condition. It can be a daily hospitalization (in case of heavy pathology requiring continuous care..), a hospitalization bi or tri weekly (in case of rehabilitation...) or occupational therapy, irregular hospitalization ( in case of occasional pathologies....). This hospitalization is also intended to relieve the family [14-15].

For one or the other type of part-time hospitalization, the transport of the patients will constitute a real problem, especially economic and financial. It remains to be demonstrated that the cost of using a pick-up bus assigned to the service and / or the reimbursement of transportation costs by the facilities taking charge of the care, added to the costs incurred by the part-time hospitalization, are lower than that of standard hospitalization.

\section{Housing for the Elderly}

Any health-care system proposed for the elderly must tend to favor home care [5-8], rejecting a priori the creation of accommodation structures (hospices, retirement homes, nursing homes). The search for better forms of accommodation is a constant of any geriatric policy, but neither the solutions proposed nor the results acquired can be the same whether in time, but also in space. The only certainty currently available to the underdeveloped countries is not to repeat the mistakes made elsewhere: they explain the current abandonment of a housing policy whose drawbacks are a fixed accommodation capacity; a faster risk of a bedridden state and psychological decline, because of an organization where everything is thought for the residents and not by themselves, of the absence or the insufficiency of structures and medical teams. The correction of these errors, must take into account the demographic evolution, the change of way of life, mentality, the demand and the wishes of the populations thus of a set of "moving" data, which can be identified only by demographic, sociological and especially gerontological and epidemiological longitudinal studies. In fact, cross-sectional surveys can not provide a satisfactory answer to all the questions asked about the risk factors of the elderly person. Psychological and social factors seem to be the most likely to influence the process of aging and must be the most important determinants of decision-making.

\section{The Geriatric Hospital-University Service}

The aim of the national university hospital center will be to carry out descriptive epidemiological studies based on longitudinal surveys, the determination of the risk factors for loss of autonomy of the elderly, the study of local factors 
influencing physical aging, the definition standards of prevention and care and the coordination of medical services interested in caring for people but also, the training of managers with the possibility of organizing staffs and weekly courses, seminars and symposia, allowing the confrontation of methods and results. This training will not only be for the use of doctors, but also for paramedical staff whose educational profiles and objectives we have defined (geriatric controller, community health worker, nurses, social workers, etc.). It will also have to a lesser extent, to interest all the disciplines concerned by gerontology as well as the decision-makers (administrator, directors of health insurance funds, planners, local elected representatives, political staff, ....).

\section{Conclusion}

Medical and health care for the elderly person in Senegal must focus on prevention without neglecting curative action [16-17]. Also, this action to be effective must be based on the maintenance at home and within the family of the elderly person, a policy of urbanization that makes possible the cohabitation of ages, the integration of geronto-geriatrics care priority health care providers and qualified staff to provide care to the elderly. This staff should include two elderly family members who are trained in the specific problems of the elderly person, a geriatric controller with a senior supervision role in villages or neighborhoods, and a community health worker trained in sanitation, a nurse specialized in geriatric care, a doctor-geriatrician, coordinator of activities, providing consultation and deciding the care or hospitalization at the departmental level of the health center. The geriatric consultation, can be integrated into the general medicine consultation, to avoid the isolation of the elderly person. Home care and day hospitalization are an alternative to traditional hospitalization; the latter, if it is unavoidable, will be a hospitalization of short or medium-term stay in a general service of medicine, or of surgery or medical or surgical specialty, with the aim of preventing the loss of autonomy or the bedridden condition, and a quick return home. A priori, the creation of a service exclusively reserved for the elderly, should for the moment be excluded. The organization that will have to cover the cost of care for the elderly remains to be defined; a participation of the elderly, educated early to "prepare their old age", as well as their family (review this paragraph) is essential if only to avoid creating a mentality assisted. A Chair in Social Gerontology, in addition to staff training, will provide a research program on the epidemiology of risk factors for loss of independence and local factors that influence aging. It will define the standards of prevention.

\section{Acknowledgements}

We thank our dear masters: Pr Ahmédou Moustapha Sow and Pr Saidou Nourou Diop (Internal Medicine Service of the
Abass Ndao Hospital in Dakar, Sénégal), Pr Anta Tal Dia (Preventive Medicine Department of the Cheikh Anta Diop University of Dakar, Sénégal), Pr Lamine Gueye Rector Alioune Diop University of Bambey, Sénégal and the entire Health and Nutrition research team.

\section{Conflict of Interest}

All the authors do not have any possible conflicts of interest.

\section{References}

[1] ONU: World Population Prospects: the 2000 Revision. New York: ONU; 2001

www.un.org/esa/population/publications/wpp2000/highlights.pdf

[2] Ministère du plan, Agence Nationale de la Statistique et de la Démographie (ANSD). Recensement général de la population et de l'habitat, de l'agriculture et de l'élevage (RGPHAE) 2013. Dakar: Ministère du Plan ANSD; 2014. 36 p. [Visité le 20/01/2016]. En ligne:

http://www.gouv.sn/IMG/pdf/Rapport provisoire RGPHAE_2013.pdf.

[3] National Agency for Statistics and Demography. Senegal: General Census of Population and Housing Agriculture and Livestock RGPHAE, Report, 2013. http://www.ansd.org.

[4] Antoine P, Fall S. Population and poverty in Dakar. In: Daffé G, Diagne A, editors. Senegalfacing the challenges of poverty: the forgotten of growth. Paris: Karthala; Dakar: CRES, CREPOS; 2008. pp. 29-50. (Men and Companies).

[5] Kâ O. GeriatricGerontology in Senegal: emergence of problems and search for solutions [Thesis of Medicine]. Dakar: Cheikh AntaDiop University; 1991. 188 p. [Visited on the 20/01/2016]. En ligne:

http://www.keneya.net/fmpos/theses/2007/med/ df/07M113.pdf.

[6] Gningue S: "The times of oldage in Senegal: intergenerational misunderstanding", Sociologies [Online], Theories and research, posted on March 07, 2014, accessed on January 17, 2017. URL: http://sociologies.revues.org/4618.

[7] O. Ka, M. Coume, C. T. Diopb, N. F. Ngomb, A. Faye, M. M. M. Leye, A. Gaye, A. A. Ndiaye, P. G. Sow, I. Seck Medico-social survey among the elderly in the gerontology and geriatrics center, Ouakam, Senegal NPG Neurologie Psychiatrie Gériatrie (2017) 17, 223-229. http://dx.doi.org/10.1016/j.npg.2016

[8] Diallo C S O: Home care for elderly people living in Ouakam: Relevance and feasibility, Dakar. Ucad, Thesis Med 2013 (04). bibnum.ucad.sn

[9] Ka O, Leye MMM, Awa Gaye, Sow PG, Tal Dia A, Diop SN and Sow AM: Towards a Geriatrics Policy Integrated to the Primary Health Care's in Africa (The Case of Senegal). J Gerontol Geriatr Res 2016, 5: 1 http://dx.doi.org/10.4172/2167-7182.100274

[10] M. Camara, I. Diagne, A. Danfa, EHM Ba et al: Psychogeriatrics in Senegal: Experience of a 10-year follow-up in a mental health center. Psychiatry, Geriatrics, Neurology; 2017, 17: 235-240. 
[11] Stille CJ, Jerant A, Bell D, Meltzer D, Elmore JG. Coordinating care across diseases, settings, and clinicians: a key rôle for the generalist in practice. Ann Intern Med. 2005; 142 (8): 700-8

[12] National Federation of Home Care Facilities (FNEHAD). Activity Report 2013. Paris: FNEHAD; 2013.

[13] Shepperd, S, Iliffe, S, Doll, HA, Clarke, MJ, Kalra, L, Wilson, $\mathrm{AD}$ and Goncalves-Bradley, DC. Admission avoidance hospital at home. Cochrane Database Syst Rev, 2016; 9. DOI: https://doi.org/10.1002/14651858.CD007491.pub2

[14] Goncalves-Bradley, DC, Iliffe, S, Doll, HA, Broad, J, Gladman, J, Langhorne, P, Richards, SH and Shepperd, S. Early discharge hospital at home. Cochrane Database Syst Rev, 2017; 6. DOI: https://doi.org/10.1002/14651858.CD000356.pub4
[15] Clément Gendrault, Anne-Laurence Caudie and Catherine Massoubre. Sequentialhospitalization: therapeuticinterest in attachmentdisorders. Psychiatric Information 2015; 5 (91): 365 to 372 .

[16] Kâ O, Gaye A, Mbacké Leye MM, Ngom NF, Dia AT, Diop SN, Sow AM. Personnes âgées et prise en charge préventive des pathologies gériatriques en milieu africain. Geriatr Psychol Neuropsychiatr Vieil 2016; $14 \quad$ (4): $363-70$ doi: 10.1684/pnv.2016.0617

[17] 15 OMS. Vieillir en bonne santé: stratégie et plan d'action. Rapport mondial de l'OMS sur le vieillissement et la santé. Genève: OMS, 2015, www.who.int/ageing/global-strategy/fr/. 